\section{Efficacy of Brodalumab vs Ustekinumab by Prior TNFa Inhibitor Exposure: Post hoc Analysis of Two Phase 3 Psoriasis Studies}

\section{OBJECTIVE}

- To evaluate the efficacy of brodalumab vs ustekinumab (an anti-interleukin- I 2/-23 monoclonal antibody) in individuals who were rescued with brodalumab or continued ustekinumab, stratified by prior treatment with tumor necrosis factor $\alpha$ (TNFa) inhibitors, in a post hoc analysis of two phase 3 studies (AMAGINE-2/-3)

\section{CONCLUSIONS}

- Patients with psoriasis who were rescued with 36 weeks of retreatment with brodalumab demonstrated higher response rates than those who continued ustekinumab, regardless of prior TNFa inhibitor treatment

- Brodalumab may be a safe and effective treatment after inadequate response to previous biologics

Alan Menter,' Erin Boh, ${ }^{2}$ George Michael Lewitt, ${ }^{3}$ Abby Jacobson

'Baylor University Medical Center, Dallas, TX; 'Tulane University School of Medicine, New Orleans, LA; ${ }^{3}$ llinois Dermatology Institute, Chicago, L; ; Ortho Dermatologics (a division of Bausch Health US, LLC), Bridgewater, NJ

\section{SYNOPSIS}

Brodalumab is a fully human interleukin- 17 receptor A antagonist approved for the treatment of moderate-to-severe plaque psoriasis in adult patients with inadequate response or loss of response to other systemic therapies'

\section{METHODS}

- In AMAGINE-2/-3 (NCT0I708603 and NCT0I708629), after a I2-week induction phase, patients received maintenance treatment as follows: brodalumab-treate patients were rerandomized to brodalumab $210 \mathrm{mg}$ every 2 weeks $(\mathrm{Q} 2 \mathrm{~W})$; receiving placebo switched to brodalumab $210 \mathrm{mg} \mathrm{Q}^{2} \mathrm{~W}^{2}$

At week 16 patients with inade

At week 16, patients with inadequate response to ustekinumab (single static

weeks) were eligible for rescue with brodalumab $210 \mathrm{mg} \mathrm{Q} 2 \mathrm{~W}$. After week 16 patients on ustekinumab with an inadequate response remained on ustekinumab Efficacy was assessed by psoriasis area and severity index $75 \%, 90 \%$, and $100 \%$ response rates (PASI 75, 90, and I00) for patients who were rescued with 36 weeks of brodalumab $210 \mathrm{mg}$ Q2W after an inadequate response to ustekinumab at week $16(\mathrm{~N}=124)$ and for patients who continued on ustekinumab after an inadequate response to ustekinumab after week $16(\mathrm{~N}=149)$, stratified by tumor necrosis factor $\alpha(\mathrm{TNF})$ inhibitor treatment before entering the study (no

\section{RESULTS}

- At week 52, after 36 weeks of retreatment, PASI 75, PASI 90, and PASI 100 brodalumab and $61.7 \%, 25.5 \%$, and $5.4 \%$ for patients who continued ustekinumab, respectively (Figure I)

Figure I. PASI rates in patients with inadequate response ${ }^{a}$ to ustekinumab rescued with brodalumab at week 16 or continuing on ustekinumab after week 16 .

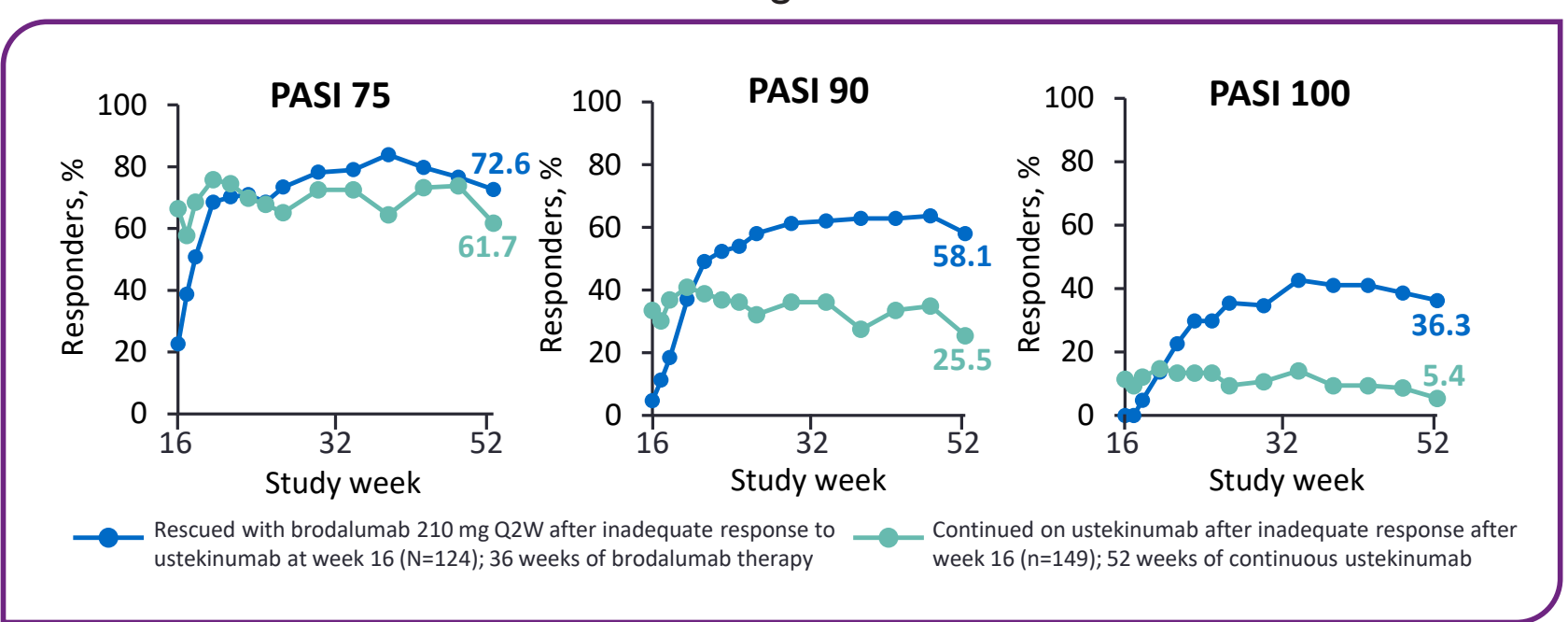

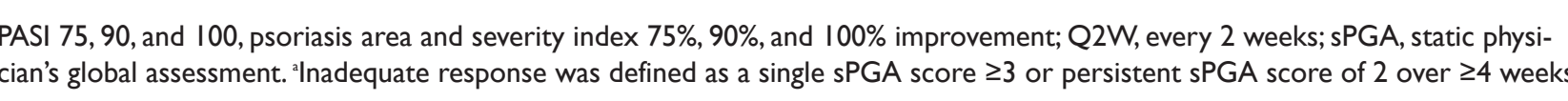

Presented at Fall Clinical Dermatology Conference • October 21-24, 2021 • Las Vegas, NV
- At week 52, patients who were rescued with brodalumab demonstrated higher ustekin, PAST 0 , and PASI 100 response rates than those who conting

Figure 2. PASI rates at week 52 in patients with inadequate response to week usteknab after week 16 , analyzed by previous TNFa inhibitor experience.

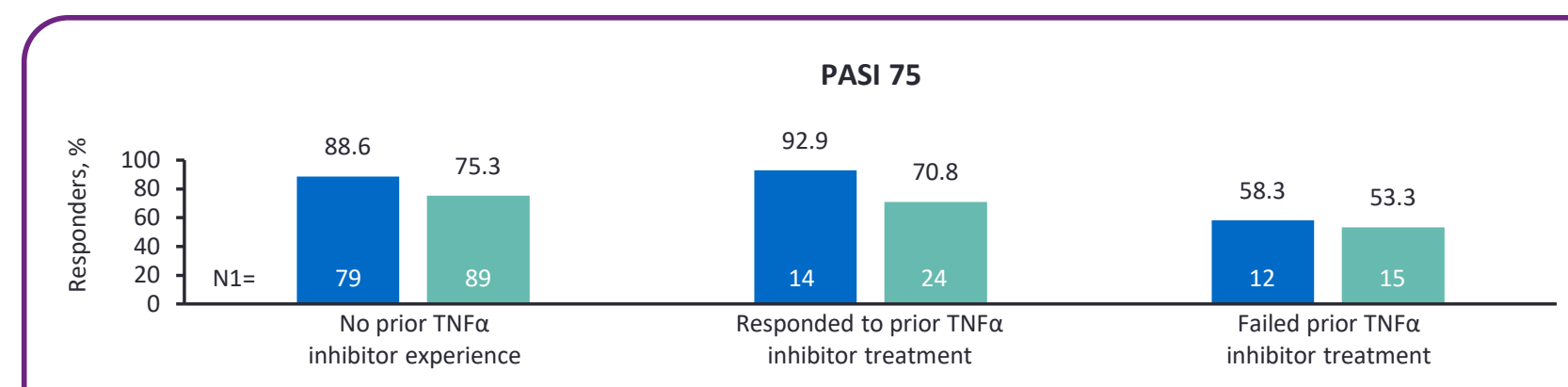

$\left.\begin{array}{c}100 \\ 80 \\ 80\end{array}\right] \quad$ PASI 90
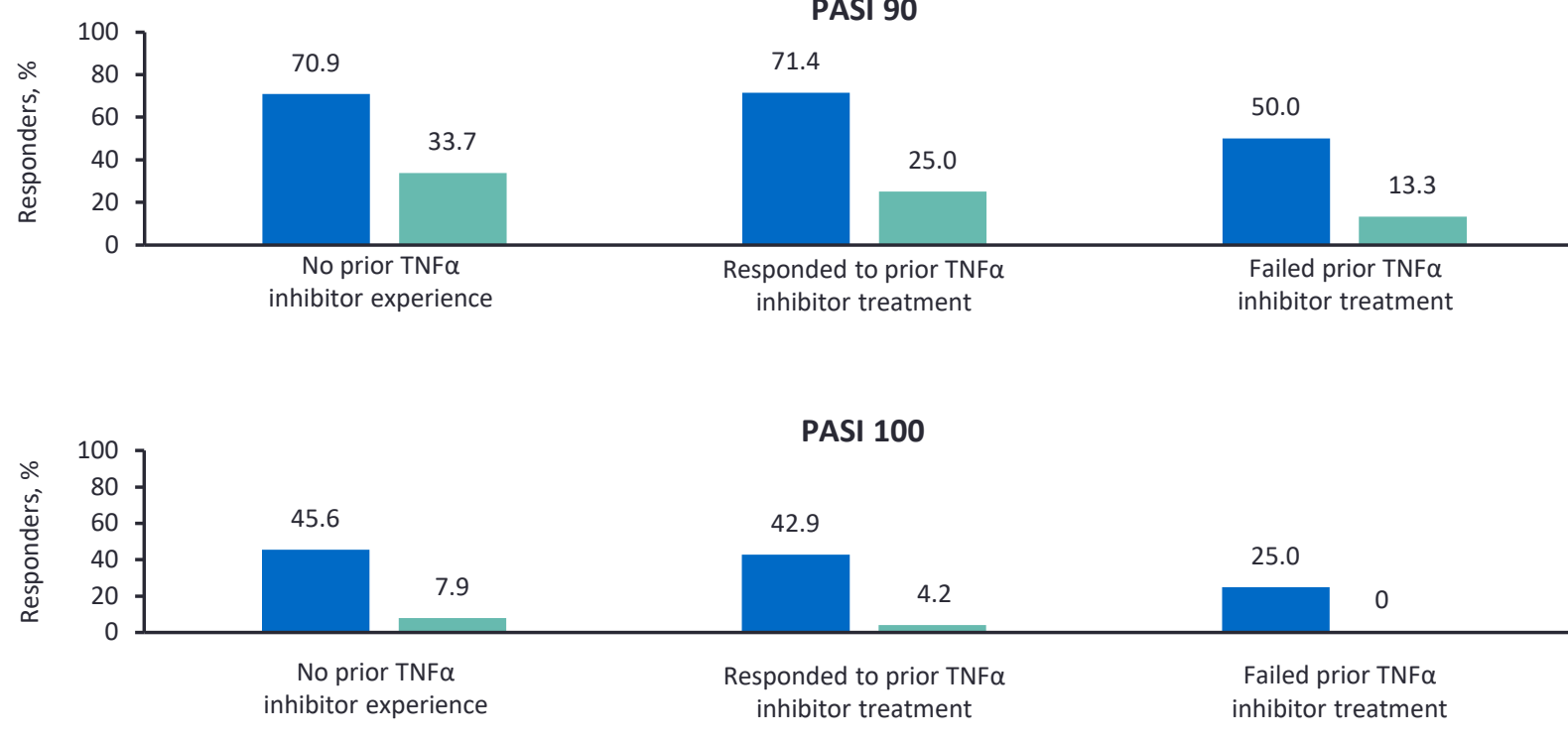

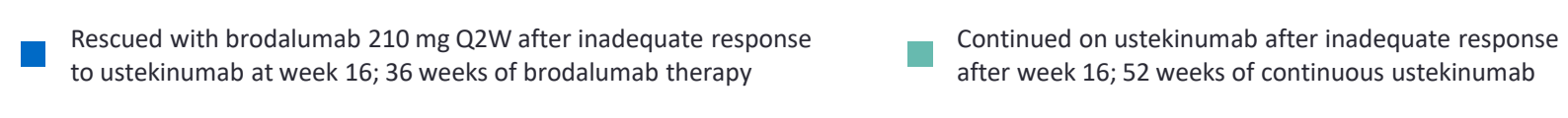

Observed analysis. N1, number of patients who had a valid measurement tat week $52 ;$ PASI 75,90 , and 100, psoriasis area and
severity index $75 \%, 90 \%$, and $100 \%$ improvement; Q2W, verery 2 weeks; TNFa, tumor necrossis factor a.

Funding: This study was sponsored by Ortho Dermatologics. Medical writing support was provided by MedThink SciCom and
funded by Orrtho Dermatologics. Ortho Dermatologicis is a division of Bausch Heath US, LLC.

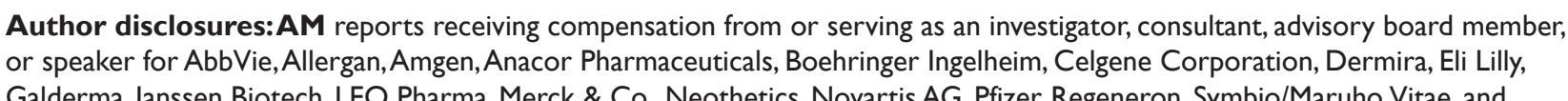

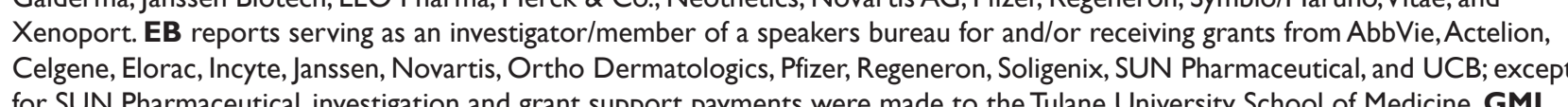
reports partnership/ownership with llinois Dermatology Institute (The Chicago Loop) and reports receiving grantstresearch

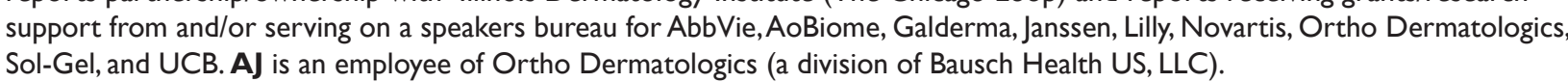
Previous presentation information: Data included in this poster have been previously presented in part at the 76th Annual
Meeting of the American Academy of Dermatology; February $16-20,208$; San Diego, CA; and Maui Derm For Dermatologistss; Meeting of the American Acachen
January $25-29,2020 ;$ Maui, $H$

References: I. Siliq [package insert]. Bausch Health US, LCC; 2017.2. Lebwohl et al. N Engl] Med. 2015;373:1318-1328. Sponsored by Ortho Dermatologics, a division of Bausch Health US, LLC 